well as tubing. Moreover, this is very economical too. Rao Karavadi rao@lehigh.edu Thu Jun 26

I don't have the answer for the tray, but I would like to make some comments about handling small samples with tweezers. I have taught the MicroCleave $e^{\text {tw }}$ technique to a lot of students at a bunch of different universities over the years. These samples have at different stages of the process very thin, fragile samples and then ultimately very, very small samples that must be handled with the sharpest tweezers available under the stereomicroscope. There are two common bad habits that students have with respect to handling samples with tweezers. One is that they try to move the sample large distances. Often they do this without a catch basin such as their cupped hand. The other bad habit that they have is not to anchor their hand while they are manipulating the tweezers to position the sample. They will have their hand in the air trying to keep their hands steady. The following are points that I always seem to have to train students to do when handling very small and delicate samples. 1. If you have to move your samples in a tweezers a long distance, then use a self-closing or one that has a sliding O-ring to keep them closed while you move them and to cup one hand under the tweezers while doing so. Better yet, put the tweezers, with the sample held clamped in the tweezers, on a tray and then move the tray. 2 . When positioning the sample, anchor the heel of your hand firmly and then just use small movements of your fingers to manipulate the tweezers. 3. If you are transferring the sample from one holder to another under a stereomicroscope, again, anchor your hand and don't move it. Lift the sample out of the holder and then move that holder out of place while holding the sample stationary and then move the second holder under the microscope under the sample. Then lower the sample into that holder. This way, the sample only makes a small distance move up and down while the hand is stabilized with the heel of your hand anchored. 4. If you can't anchor your hand on the desktop because you have to have the tweezers high off the desktop, then get a block, brick, or box that is rigid so that you can raise your hands to the correct height and still anchor the heel of your hand. 5. If you have delicate samples, then don't drink coffee or be hungry while you have to do the work, otherwise your hands will shake too much. 6 . Never hold your samples where there is nothing to catch them other than the floor. If your hands aren't far from the table top, then they won't go far when you drop them. (Notice I said "when" and not "if".) 7. If you get a choice of colors for bench tops and counters, go with a single color, never go with a pattern, especially patterns that look like granite! Otherwise, you won't even find a screw that falls on the tabletop, let alone a sample. Scott D. Walck walck@southbaytech.com Thu Jun 26

You might try a surplus outlet for electronics manufacturing equipment to obtain an inexpensive "vacuum tweezers" or die pickand-place device. This consists of a tiny vacuum wand (shaped a bit like an airbrush sprayer) with a soft tip and a finger-controlled push button valve to release the vacuum. In its intended use, it is used to pick up a bare silicon chip (integrated circuit or "die") and set it down where it is to be bonded to a substrate. Tips are available that are small enough to handle a chip that is 20 thousandths of an inch square, or so. The vacuum can be provided by something as simple as an aquarium pump since the airflow is minimal. John Twilley jtwilley@sprynet.com Thu Jun 26

\section{Microscopy Today Gets a New Editor}

\author{
Ron Anderson \\ Microscopy Today Editor \\ randerson20@tampabay.rr.com
}

Nothing lasts forever. After retiring from IBM after a 42-year career in 2001 I was honored by the Microscopy Society of America with their trust when they appointed me Editor of Microscopy Today. MSA bought MT from its founding editor, Don Grimes, in 2002 and I assumed the editorship in April of 2002. The May 2002 issue was my first. My use of the singular "I" and "my" is not correct. From the beginning, my wife, Dale Anderson, was the other half of the MT team as Art Director and proof reader. She was responsible for the redesign of the magazine that was introduced with the July 2002 issue and selects and creates the cover eye-candy.

As much as we enjoy producing MT, we have to recognize that we are both into our seventies and it is time to retire for good.

MSA has appointed Charlie Lyman, Lehigh University, as the new editor effective January 1,2009. Charlie is coming off of nearly a decade as editor of MSA's journal, Microscopy and Microanalysis. I have told Charlie that I will stay on to help him where ever and for as long as he needs me. Dale and I plan to attend M\&M meetings into the future and look forward to seeing many of you there.

Dale and I would be remiss if we did not thank the many people who have made MT what it is today.

- Phil Oshel is Technical Editor. He has procured many articles for MT and has been a resource for MT with regard to biological science issues. Phil performed the same function for Don Grimes.

- Tom Phillips, Contributing Editor, provides us with NetNotesone of our most popular features.

- Renée Stratmoen, Advertising Director, helps provide the advertisements.

- Jon Shields, AKA Dear Abbe, brought humor to the pages of MT.

- Stephen Carmichael whose one-hundred and fifth (105!) consecutive "Carmichael Article" is in this issue!

- Nestor Zaluzec designed our website, automated the subscription process and saw to the creation of a downloadable archive of all past MT issues.

- The authors of all of the articles we published. The authors range from high school kids to all level of amateur and professional microscopists to retirees. Some authors have submitted more than five articles. You have made MT the respected publication it is today!

- All of us are grateful to the advertisers who have made MT financially viable. Without them there would be no MT. Their advertisements are technically and artistically superb. On a personal level, the many warm friends that we have made with the fine people who work for the advertisers and who place the ads is a treasure.

We look forward to enjoying our children and grandchildren, staying active as volunteers for our church and local symphony orchestra, staying in touch with microscopy one way or another, and living the Florida retiree lifestyle (whatever that is). Please feel free to e-mail us at the address above from time to time.

\section{Ron and Dale Anderson}

